\title{
How perceived organizational politics cause work-to-family conflict? Scoping and systematic review of literature
}

\author{
Sumbol Fiaz ${ }^{*}$ (i) and Muhammad Azeem Qureshi
}

\begin{abstract}
Work-family conflict is a subject of interest for researchers in the field of organizational behavior for decades because of its negative impact on an individual's life. The existing literature identified that workplace stressors contribute to work-family conflict and Perceived Organizational Politics emerged as an aversive workplace stressor. From empirical pieces of evidence, it is observed that perceived organizational politics and work-family conflict are indirectly associated with each other, and their impact on employees is unavoidable. To explore this uncovered relationship, at first, this study used a keywords co-occurrence network mapping approach and found that perceived organizational politics and work-family conflict are associated with each through various workplace variables. Further, with the help of a scoping review identify those specific variables, and, lastly, a systematic review approach used to identify a mechanism of how these identified variables form an association between perceived organizational politics and work-family conflict. Based on the findings of the systematic review, this study proposed a conceptual framework that extends the existing literature by providing new insight into concepts of perceived organizational politics by linking it with work-family conflict. This study introduced a novel way to develop a conceptual framework by linking three distinct approaches of research. In the last, this study proposed recommendations for future research.
\end{abstract}

Keywords: Perceived organizational politics, Work-to-family conflict, Negative affectivity, Emotional intelligence, Psychological wellbeing, Perceived organizational support, Social support, Organizational behavior

\section{Introduction}

Work-family conflict is the most debated construct in the field of organizational behavior that has gotten the central attention of researchers due to its negative consequences related to the workplace [47, 111]. Facing conflict at work and family domain is a burning issue for which employees mostly complain. Conflict in one domain ultimately affects the other domain. Employees are more concerned about keeping it balanced because of its impacts on their efficiency and wellbeing [88]. Workfamily conflict is strongly associated with an employee's wellbeing [101]. While wellbeing depends on the state

*Correspondence: Std_22827@iobm.edu.pk

Institute of Business Management, Omer Chamber 2nd Floor Akbar Manzil Street, Korangi Creek, Karachi 75190, Sindh, Pakistan of emotions, positive emotions satisfy whereas negative emotions disturb wellbeing $[48,137]$ and strongly associated with individuals' behavior. Employees experience several behaviors in the workplace that impacts their emotions. In the domain of organizational behavior, Perceived Organizational Politics is the most dominant and influencing work-related negative factor that impacts the employees' behavior [114]. It is a general phenomenon in all organizations that are usually perceived negatively and results in undesirable or harmful outcomes such as stress that is one of the most prominent outcomes $[29,44,78$, 144].

Experience is an outcome of an individual's evaluation of specific phenomena or events [102]. Employees on this basis of their experience define organizational politics as cynical and manipulative phenomena, they describe it as an evil behavior that employees strategically show 
to get the things done for their benefit by disturbing the organization's functions $[38,41,45,51,79,90]$ and also risking the wellbeing of other employees and organization [70]. When employees experience organizational politics they think themselves as a victim who has to suffer due to others' self-serving behavior. Consequently, this situation evokes negative emotions [128]. Employees spend most of their time at the workplace [87]. Therefore, work-related circumstances govern their emotions and behavior, experience of adverse events at the workplace predict the negative emotions and cause stress [96] that ultimately impacts the wellbeing of the employee.

Work and family are the most important factors in almost every individual's life. When the occurrence of stress due to participation in one domain become a constrain and makes it challenging to fulfill the requirement of other domain this known as work-family conflict (WFC) [54]. Work-family conflict has been a subject of interest in the field of organizational behavior for decades, a constant increase in its body of literature raising the importance of work-family conflict [120]. Currently, it has gotten remarkable attention from researchers due to its negative consequences for work and family domain $[47,111]$. Existing research demonstrated that negative work-related factors such as stress predict work-family conflict [14] while Perceived organizational politics (POP) is identified as one of the most dominant and influencing negative aspects of the work environment [78, 80]. POP is an uncovered work-related factor that affects both the personal and professional lives of employees and causes WFC. To prevent this uncovered cause of WFC, it is required to identify how POP causing WFC. There is an extensive number of studies explored the consequences of perceived organizational politics related to the work domain. There is no significant predictive model for understanding how POP impacts the WFC. It is a clear research gap that needs to be addressed.

To strengthen of above argument that there are factors indirectly causing the relationship of POP and WFC, with the help of VOSviewer software [142] this study also created the keyword co-occurrence network to map out all variables that have been studied in the field of POP and WFC. VOSviewer is a software tool that creates a map based on network data retrieved through search engines or databases. Microsoft Academic (MA) database was used with VOSviewer software. MA is a huge database that allows downloading already segmented citation contexts [19]. Key terms used to get the search data were Perceived Organizational Politics. The mapbased on keywords occurrence network, generated through option, "title and abstract network". This function of VOSviewer retrieved the keywords that appear in the title, abstract, and citation context [146]. The setting of VOSviewer was done in such a manner that it captured all the key variables that occurred in abstracts and titles, at least four times. Full counting of words was applied. From the retrieved keywords, before generating the map, irrelevant keywords that were not described as variables in the literature such as structural equation modeling, mediators, moderators, negative relation, were manually excluded. As argued Fig. 1 shown that the concept of POP is linking with all the work domain variables that are getting the effect of or affecting POP. This map supports our argument that existing researches focused on only work-related outcomes of POP.

The same procedure has been followed with the key term work-to-family conflict, to map out the most highlighted variables that explored or examine concern to work-to-family conflict. Figure 2 reflects the variable network concerning WFC. Map 2 highlighted all the variables that have been studied in the field of WFC. From the analysis of both maps shown in Figs. 1 and 2, it can be seen that many identical variables are related to POP and WFC at the same time such as job stress, emotional intelligence, turnover intention. So, it can be argued that some of the outcome variables of POP are antecedents of WFC. Since we did not specify the key terms as an antecedent and outcome, therefore, we are unable to distinct that either linked variables are antecedents or outcomes. To address this issue and identify the specific factors that link these two vast domains of organizational behavior, i.e., POP and WFC, the present study conducted a scoping review. The purpose of the scoping review is to find out the identical variables that are outcomes of WFC and also antecedents of WFC. And also describe the reason for considering those identified variables.

\section{Scoping review}

For this study, the scoping review aims to establish a comprehensive review of published literature and identify the key variables that can predict the relationship between OP and WFC. The scoping review is conducted by following the advanced framework of Arksey and O'Malley described in Scoping studies: Advancing the Methodology [82]. The methodology of scoping studies is based on six systematic phases shown in Fig. 3.

\section{Defining research question}

WFC is a subject of interest for researchers. It is a cyclic process; conflicts at one domain trigger the conflicts at other domains. Findings of studies revealed that the predictors of work-to-family conflicts are similar across the world [6]. Factors associated with the workplace severely impact employees' lives than on family-related factors $[35,64,138]$. POP is one of the significant aspects of a workplace that influences employees' personal and 


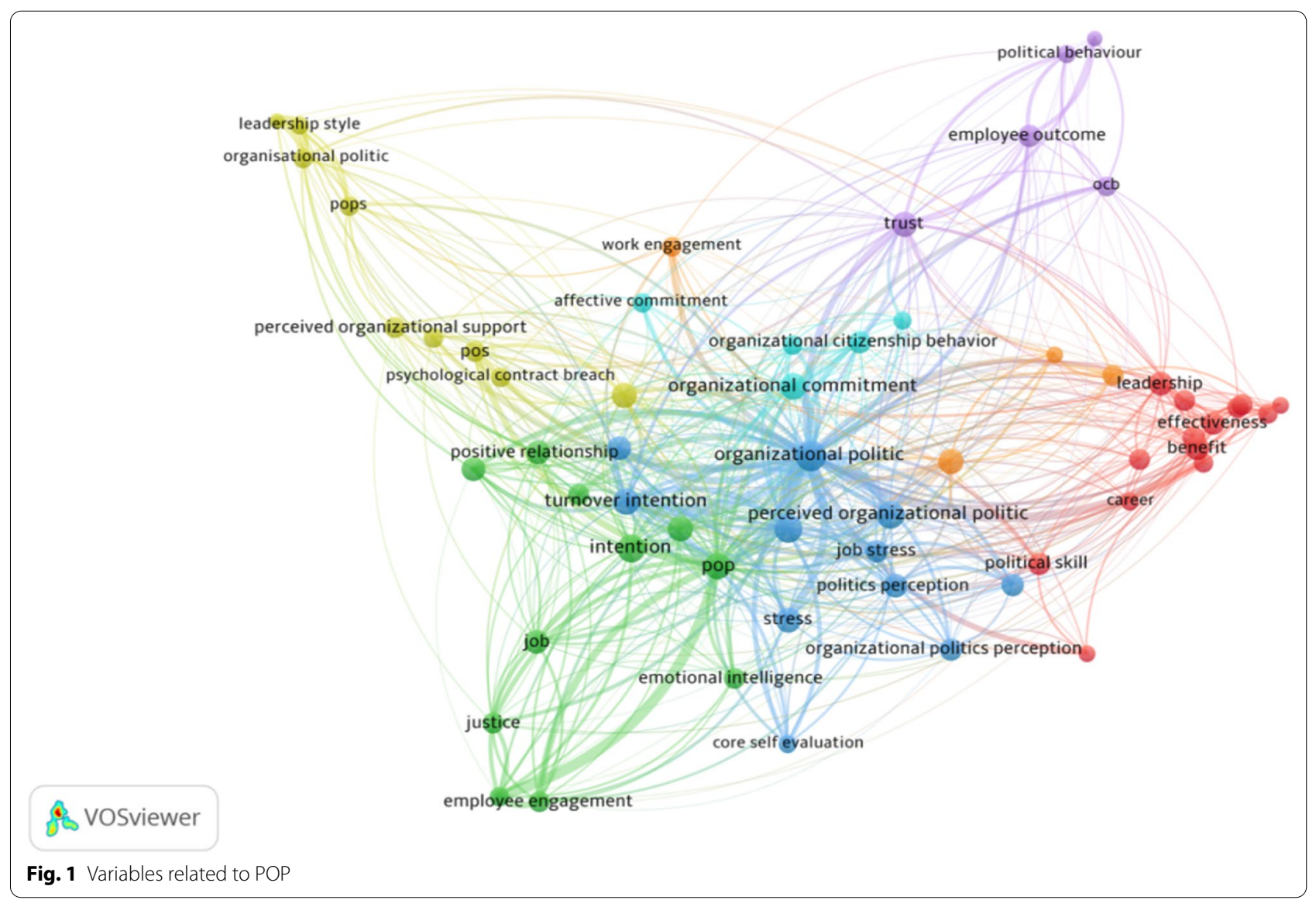

professional life. Both factors of organizational behavior are indirectly related to each other. The scope of this review is to identify:

What are the factors that bridge the association of perceived organizational politics and work-family conflict?

\section{Identifying the relevant studies}

To address the research question, this study considered that all the related studies reported the consequences of perceived organizational politics and antecedents of work-family conflicts. The literature search was conducted with the intent to find out the variables that bridge these two broad research areas of organizational behavior. For this purpose, this study employed the search databases, i.e., Elsevier BV, Sage Publication, Wiley Online, Springer nature, American psychological Association, Taylor and Francis., JSTOR, Frontiers Media S.A., Emerald, INFORMS, The Academy of Management, NCBI, MDPI, Public Library of Science, Cambridge University Press, EBSCO host, SSRN, PsycINFO and IEEE Xplore, to get all the relevant research articles, book sections, and dissertations (M.Phill. \& Ph.D. level). This study developed two search terms for literature search are:
1. Consequence OR Outcomes OR relationship of OR Impact of AND Organizational Politics OR Perception of organizational politics, Office politics OR Political behavior at workplace OR Politics at the workplace.

2. Antecedents OR Predictors OR Sources of OR impact on AND work-family conflict OR work-life conflict OR work-family interference OR work-tofamily conflict.

Studies containing any of these described keywords were selected. Similar search terms were used for all the databases.

\section{Study selection}

By following [82] guidelines for scoping review, established a team of three researchers included two independent reviewers and one arbitrator. The study selection process based on inclusion and exclusion criteria is carried out by two independent reviewers to maintain transparency and avoid uncertainty about the outcomes of the review. The same reviewers defined the inclusion and exclusion criteria for the studies that have been considered for this review with mutual understanding. In case 

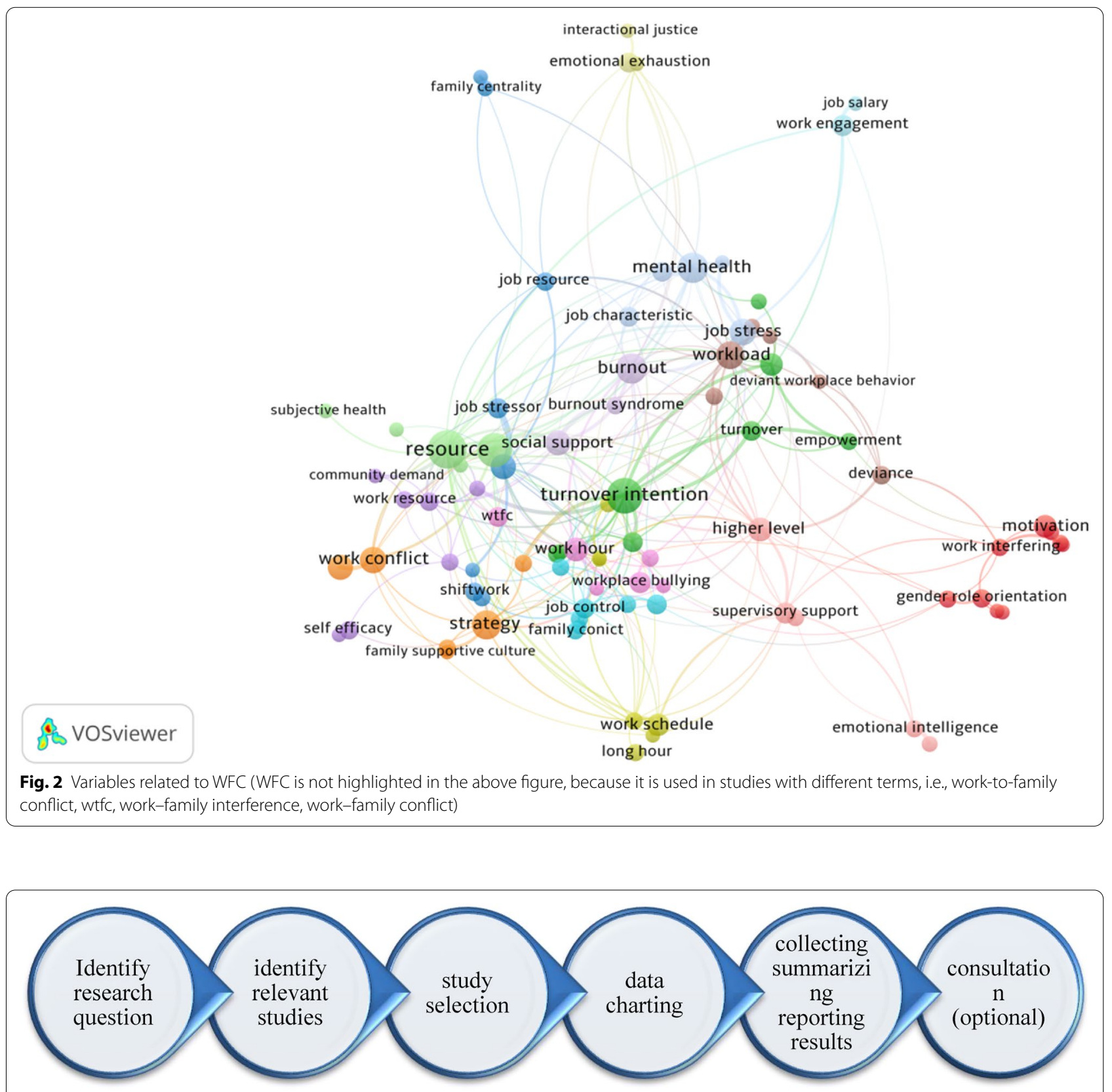

Fig. 3 Process of Scoping Review

of disagreement while selecting studies got consultation from an arbitrator to resolve the dispute and to determine the final participation. Studies indicating the outcome variables or consequence of POP and preceding variables of WFC retained. Inclusion and exclusion criteria for study selection shown in Table 1.

The searched citations are managed through opensource citation management software Zotero. The study selection process of identified studies is shown in Fig. 4 PRISMA Flow diagram.

\section{Charting the data}

Data charting is a process at which both the reviewers collectively extract the required information from the selected studies to address the research question. Data 
Table 1 Inclusion and exclusion criteria

\begin{tabular}{|c|c|c|}
\hline Focused content & Inclusion criteria & Exclusion criteria \\
\hline Language & English & Other than English \\
\hline Year of publication & Since the inception of constructs until December 2019 & - \\
\hline Study type & $\begin{array}{l}\text { Research articles (published by well curated databases and } \\
\text { locally published in HEC recognized journals), with good } \\
\text { methodological quality, thesis and dissertation (M.Phill. \& PhD } \\
\text { level) published by QS ranking universities, book chapters/ } \\
\text { section, reviews }\end{array}$ & $\begin{array}{l}\text { Newspapers, magazines, the thesis of Graduate \& Masters level, } \\
\text { conference proceeding } \\
\text { Reason: Grey Literature }\end{array}$ \\
\hline Study findings & $\begin{array}{l}\text { Indicating outcome variables of organizational politics and } \\
\text { predicting variables of work-family conflict }\end{array}$ & $\begin{array}{l}\text { Outcomes of work-family conflict and antecedents of organiza- } \\
\text { tional politics studied. Each variable separately studied } \\
\text { POP and WFC examined as mediator or moderator } \\
\text { Reason: not related to the objective of this review }\end{array}$ \\
\hline
\end{tabular}

extracted through Data Charting Form (DCF), developed with the mutual consultation of reviewers. Before starting the data charting, reviewers conducted a pilot test of established DCF on randomly selected five studies to validate that the data charting approach is appropriate for achieving the aim of scoping review. After the pilot test, DCF has refined accordingly. The data extracted in a qualitative manner, which was analyzed through the content analysis approach. Retained studies were separately analyzed to obtain the outcome variables of POP and anteceding variables of WFC. An arbitrator critically reviewed the extracted data. Following are the data items retrieved from the selected studies

- Study characteristics (Author name, Journal name, year of publication, study design, population and sample size)

- The objective of the study

- Examine or identified variables as (antecedents of WFC and Outcomes of POP)

- Findings/results/conclusion of the study

\section{Collating, summarizing, and reporting results}

Extracted data were organized by using Microsoft excel. Separate word files created of antecedents of WFC and outcome variables of POP. Manually identified the similar variables from both the separated files. Burnout, Emotional intelligence, Job involvement, Negative Affectivity, Psychological wellbeing, Perceived Organizational Support, and Social support are variables identified from literature through scoping review that may support the relationship between POP and WFC by acting as mediator or moderator. Afterword conducted a content analysis to describe the results of the scoping review.

\section{Results}

From the search results, one research has identified that examined the impact of POP other than the work domain. A study conducted by Zhu and Li [154], based on ecological system theory [21] and boundary theory [9], examined the influence of POP on WFC. They hypothesized that WFC is an outcome of workplace environmental situations that are stressors. They consider POP as a workplace stressor that harms the boundary of work and family domain and makes it difficult for individuals to perform the family role. In line with the stimulus-responses model, they also hypothesized that organizational cynicism (Attitude) mediate (bridge) the relationship between OP (stimulus/event) and WFC (response). Little literature support was found for their research model therefore it identified as detailed research that needs to address. In this section as first defined the identified variables. Secondly, based on the content analysis of the findings of retained studies this section described the reason for considering these identified variables for further study.

\section{Burnout}

Psychological health issues harm individuals' life [104]. Burnout is a major psychological health problem around the world. It is a prolonged human response against the chronic emotional and interpersonal stressors on the job, which is expressed through exhaustion, cynicism, and professional inefficacy [94, p. 351]. Burnout is an outcome of workplace stressors that prevent employees from achieving their organizational related goals and expectation [110]. Whereas POP highlighted as a workplace stressor $[22,152]$ and a strong predictor of burnout $[78,91]$. From the analysis of studies, it has been identified that when an employee perceive the workplace as political, it affects the psychological health of employee that intensify the burnout $[16,37]$. Burnout is a dominant 


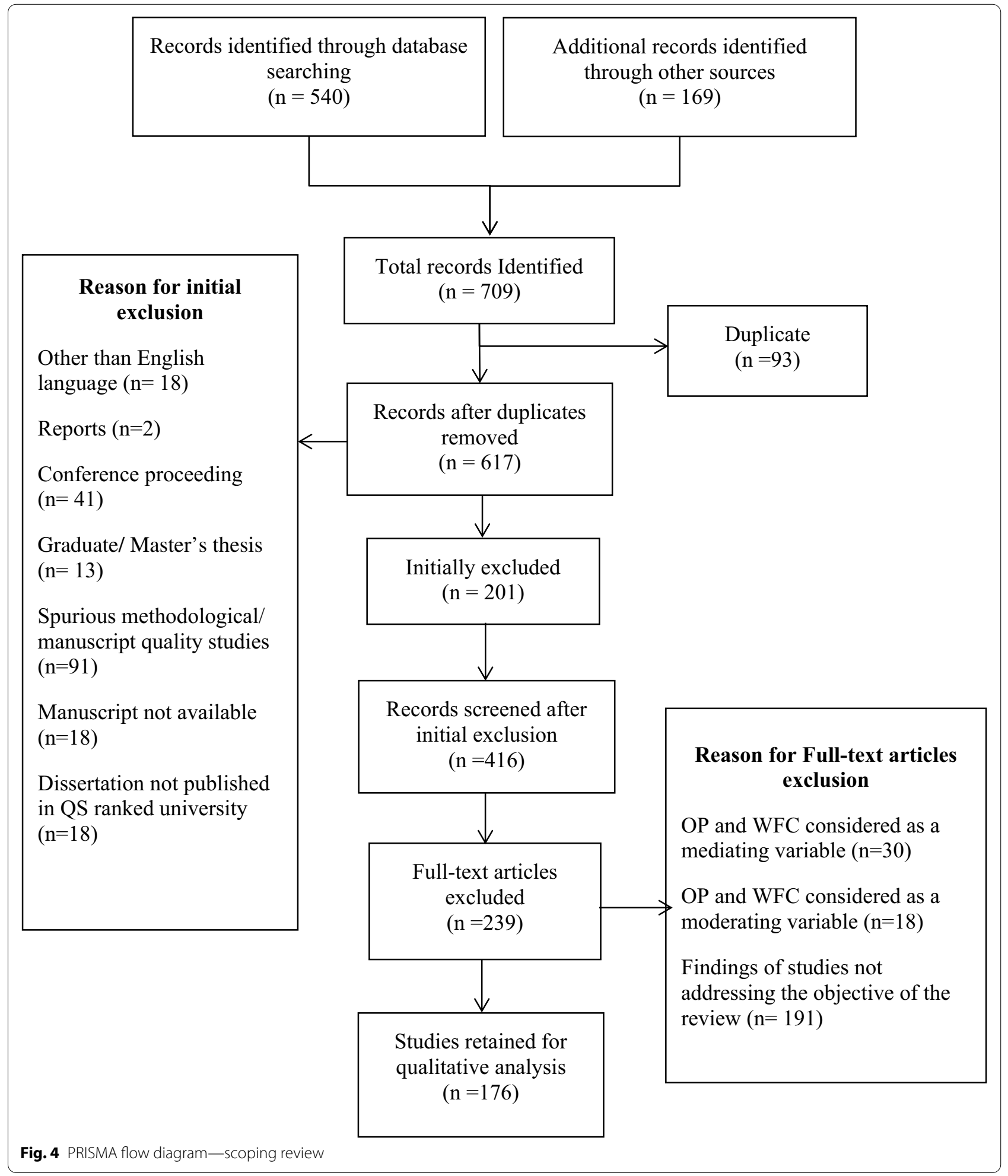

workplace factor that has a strong tie with the health and wellbeing of employees [94, p. 351]. It has a detrimental impact on employees' family and professional life [129]. Studies have identified a positive association between
WFC and burnout. Studies predict burnout as a consequent factor that happens due to WFC [25, 46]. Although burnout is identified as a common variable through analysis current literature has not found any strong literature 
support for burnout as an antecedent of WFC due to which this study has not considered Burnout for further examination.

\section{Emotional intelligence}

Emotional intelligence is an ability to rational or unbiased identification of emotions, perceive emotions based on reality, understanding their true meaning, and manage them accordingly [97, 98]. Emotional intelligence is a strength of character that allows individuals to control emotions [122]. POP is all about the individual's perception of certain behaviors as apolitical. Due to not having emotional and intellectual skills, employees perceive certain behaviors in an organization as political, which swings the employees' emotions [37, 131]. While WFC is a resultant phenomenon of individuals' negative behavior. EI has identified as a bulbous variable in the study of POP that varies the intensity POP. Findings of the studies have revealed that emotional intelligence enhances individual emotional and intellectual capacity, lets him accurately identify the behaviors, and acts accordingly [37, 63, 89]. Similarly, studies related to WFC also highlighted EI as a factor that is strongly associated with WFC $[69,81]$. Since the study found this variable as a factor that may predict the relationship between POP and WFC so it will be considered for further research to define its role.

\section{Job involvement}

Job involvement is referred to as a psychological attachment of individuals with their job, and their personality well described by his nature of current work $[85,116]$. A person with high job involvement would be highly concern with the job matter and put extra time and effort into a job [68]. Findings of the review identified job involvement as a consequent variable of $\mathrm{OP}$ and antecedent of WFC. Results of studies indicated that POP has an adverse impact on job involvement [117]. Perception of OP decreases the level of job involvement. When employees perceive the workplace as political or perceive political behavior at the workplace, it lowers their involvement in a job $[11,18,117,130]$. In the meantime, job involvement has also been identified as a strong predictor of WFC [27]. High job involvement increases the employees' concentration toward job due to which employees pay less attention toward the performance of a role in the family domain that causes the WFC $[59,99,111]$. Although job involvement is found as a shared variable, the role of this variable is contrary. From the analysis of retained studies, it revealed that job involvement is not a factor that may lead POP to WFC. POP lowers employee job involvement [117], which may reduce the chances of WFC. Whereas high job involvement reduces negative perception about POP. Based on the above-described analysis, role of the job involvement seems ambiguous; therefore, this study neglected the construct job involvement to consider as a possible mediator or moderator in the relationship of POP and WFC.

\section{Negative affectivity}

Negative affectivity (NA) is a mental health outcome [126]. It is a dispositional tendency at which individual experiences various states of negative mood [147]. It is described as an aversive, undesirable or uncomfortable state of emotions and self-concept at which a person feels anxiety, worry, depression fear, or anger [28, 71, 119, 148]. The literature described its positive association POP [140]. Employees who perceive the workplace environment as political their level of negative affectivity is high. Because POP consider as negative workplace factor and it induces insecurity within employees as a result employees feel NA. Consequently literature also showed a positive association between NA and WFC, employees who experience NA due to workplace stressors they more likely to encounter WFC [132]. Hence NA is identified as a stimulus that bridges the relation of POP and WFC therefore NA is considered for further study.

\section{Psychological wellbeing}

In the research of behavioral interventions, psychological wellbeing (PWB) has been used as an outcome variable that is affected due to adverse events [150]. Psychological wellbeing is defined as a presence of positive psychological adjustment indicators such as positive emotions, happiness, high self-esteem, life satisfaction, and absence of psychological maladjustment indicators such as negative emotions and psychopathological symptoms [62]. The emotional stability of an individual predicts PWB. POP is a negative workplace factor that disturbed the stability of emotions [79] and harms the psychological wellbeing of employees [141]. Employees with unstable psychological wellbeing due to workplace problems fail to perform their family roles and as result encounter the work-family conflict [101]. From an analysis of the scoping review, PWB has also identified as a variable that may lead POP to WFC and it is necessary to identify in what manner PWB would participate while causing this relation. Therefore, this study retained PWB for further systematic review.

\section{Perceived organizational support}

Eisenberger et al. [39] described perceived organizational support (POS) as an employee's perception that his organization value his contribution and care for his wellbeing. Employee perceives that the organization will support him whenever needed to carry on the job effectively and to deal with a stressful situation [118]. POS is 
workplace support. Positive perception about organizational support encourages an employee to concern for organizational welfare and objective [40]. It strongly predicts the employee's orientation toward the organization and work, employee performance, and wellbeing [76]. In contrast, the perception of OP demotes employees associated with the organization but high POS will permit employees to perceive their workplace or workplace behavior as political $[17,58,121]$. POS impacts the employees' behavior and works attitude [23, 26]; meanwhile, POS is inversely associated with $\operatorname{WFC}[55,75]$. The findings of the scoping review found a negative association between both the variables POP and WFC with POS. Hence from these findings, it is not clear how POS predicts this relation and it needs to be identified.

\section{Social support}

From the analysis of retained studies, we have identified a construct of social support that has frequently been examined. Social support is an instrumental or emotional aid from work or family domain which intends to secure or enhance the wellbeing $[95,136]$. Social support is broadly classified into two categories, i.e., perceived social support and received social support [139]. Findings of the studies have shown a strong association of received social support from family, supervisor, coworkers, and friends with WFC $[57,59,66]$. When employees experience conflict in either work or family domain upon receiving social support from work or the family domain conflict alleviates [49, 134]. Similarly when employees perceive workplace politics that causes stress and made them realize to get harm at that time provision of social support will reduce the adverse effects of POP that may harm his wellbeing $[58,144]$. Based on the above literature support, it can be said that social support not only enables employees to overcome the WFC but also a barrier for harming the impact of POP. It is reasonable for this study to further explore the way through which social support participates in the relationship between POP and WFC. Although findings of the scoping review identified both dimensions of social support, i.e., work and family, but through the content, analysis is found that only work-related dimensions of social support reduce the aftermaths of POP [144]. Therefore, this study is considered an only work-related dimension of social support.

From the above analysis, this study has identified the variable that can predict the relationship between POP and WFC, i.e., Emotional intelligence, Negative Affectivity, Psychological wellbeing, Perceived Organizational Support, Workplace Social support. To find out how these identified variables determine the path of OP toward the WFC and to get an in-depth understanding of this hypothesized relation, it is required to analyze and synthesize existing literature critically. Due to this purpose, this study proceed to conduct a systematic review.

\section{Systematic literature review}

As the objective of this study is to explore the relationship between POP and WFC. In this study, scoping review helped to identify the variables and how these are related to POP and WFC, but findings are not enough to define the relation of these variables with each other. To conclude the findings of the scoping review and formulate, the comprehensive model to describe the way through which identified variables predict the relationship of POP and WFC systematic review for this study conducted.

The systematic review has been conducted by following the guidelines of Pollock and Berge [112]. According to their guidelines, the procedure for conducting systematic review consists of six consecutive phases, namely (i) clarify research aims and objectives, (ii) performing literature search (finding relevant research), (iii) data collection/ extraction, (iv) assess the quality of studies, (v) synthesize evidence and (vi) interpret findings.

\section{Clarifying the aim and objectives Defining a research objective}

POP and WFC are two of the critical and significant concepts of organizational behavior. Through an extensive search, it has found that these factors highly influencing the organizational and personal life of employees. To cope with any conflicting matter, it is necessary to have an in-depth understanding of it. Although from the findings of two approaches, i.e., Network map and Scoping review, it is proved that POP and WFC are related to each other through specific work-related factors but there is no predictive significant model available to understand and described this relationship. Therefore, the objective of this systematic review is to define the role of all the variables to establish a comprehensive conceptual model.

\section{Formulating eligibility criteria}

This study included all the empirical studies with qualitative, quantitative, or mixed-methodology and books published in the English language reporting relationship between identified variables through scoping review since their inception. The search for the dissertation was also made to include all the published pieces of evidence. Manuscripts that provide evidence related to the research objective, either positive or negative, were considered. All the published studies and books in which any of these variables separately studied, their relationship has been examined with other variables, examine as a mediating or moderating variable, findings showing an insignificant relationship among identified variables, studies other than the English language, not considered 
for this research excluded. Conference proceedings, publications with poor quality, and not published in curated journals/databases include thesis and dissertation excluded. To attain the generalizability of this review, all the studies are conducted for employees with chronic illness, patients, pregnant women, employees with physical/intellectual disabilities excluded because the mental state and environmental conditions of these employees are different from general employees and finding of these studies may impact the original findings. Grey literature was also excluded.

\section{Literature search}

\section{Defining search strategy}

The search considered databases that publish studies specific to organizational behavior and industrial/ organizational/business psychology. The literature search conducted by using the following electronic databases: Elsevier BV, Sage Publication, Wiley Online, Springer nature, American psychological Association, JSTOR, Frontiers Media S.A., Emerald, The Academy of Management, Public Library of Science, Cambridge University Press, ERIC, EBSCO host, SSRN, PsycINFO, Taylor \& Francis, ProQuest theses \& dissertations, NCBI, IEEE Xplore. For an adequate literature search, it required to use broad search terms, i.e., keywords and free text words [115], The search terms used in this study for literature search are Negative Affectivity AND Emotional Intelligence AND/OR Psychological Well-being/wellbeing AND/ OR Perceived Organizational Support AND/OR Social support. Studies containing any of these described keywords were selected. Similar search terms were used for all the databases. Social support is a multidimensional construct, and it has observed that most of the studies used a keyword "social support" as a whole so instead of pointing its dimension that has considered in the study. To include all the relevant studies or evidence, this study used a search term "Social Support."

A vast number of studies have been conducted in connection with the identified variables. Peer-reviewed publications, book sections, thesis, and dissertation have been identified through the electronic databases. Additional publications search through search engines, i.e., Google Scholar, Microsoft Academic Search, and Crossref, by using keywords described in the search strategy. Overall, 468 studies have identified in which 229 studies retrieved from database search and 246 studies identified through manual search via a search engine, i.e., Google scholar. Details of studies retrieved from databases are shown in Table 2.
Table 2 Database search result

\begin{tabular}{lc}
\hline Data bases & $\begin{array}{c}\text { No. } \\
\text { of studies } \\
\text { identified }\end{array}$ \\
\hline Ebsco host & 5 \\
elibrary.ru & 21 \\
Elsevier & 24 \\
Emerald insight.com & 3 \\
ERIC & 4 \\
frontiers in & 2 \\
JSTOR & 3 \\
NCBI & 5 \\
Proquest & 25 \\
Psych net.APA.org & 11 \\
Sage pub & 23 \\
Semantic Scholar & 15 \\
Springer & 19 \\
SSRN & 3 \\
Taylor \& Francis & 33 \\
Wiley Online Library & 33 \\
Total & 229 \\
\hline
\end{tabular}

\section{Selection of abstract and full-text article}

As per Chocrane guideline [50], selection of abstract and full-text articles was carried out by two independent reviewers to reduce bias while selecting and interpreting the content. Differences and disputes while selecting articles were discussed and resolved by the arbitrator. Studies that meet the above-described eligibility criteria were selected. Search results are managed by using free and open-source reference management software Zotero to keep an adequate record of developing a proper PRISMA flowchart.

Eligibility of identified studies based on predefined inclusion criteria initially evaluated through abstract and introductory sections of studies, i.e., study type, language, impact factor/HEC recognized journal. Two hundred forty-four studies have initially excluded (with reason) that were not meeting any of the inclusion criteria. Afterward, reviewed 231 full-text studies and an additional 196 studies excluded with documented reasons. Detailed characteristics of excluded studies are presented in the PRISMA flow diagram (Fig. 5).

\section{Data extraction}

Data extracted from the selected studies by adopting a data extraction form of Cochrane collaboration [32]. General information of article, i.e., title, author, publication year and journal name, the objective of the research, study design, statistical techniques, results, and conclusion extracted from selected studies. Required information of all the retained studies presents through textual 


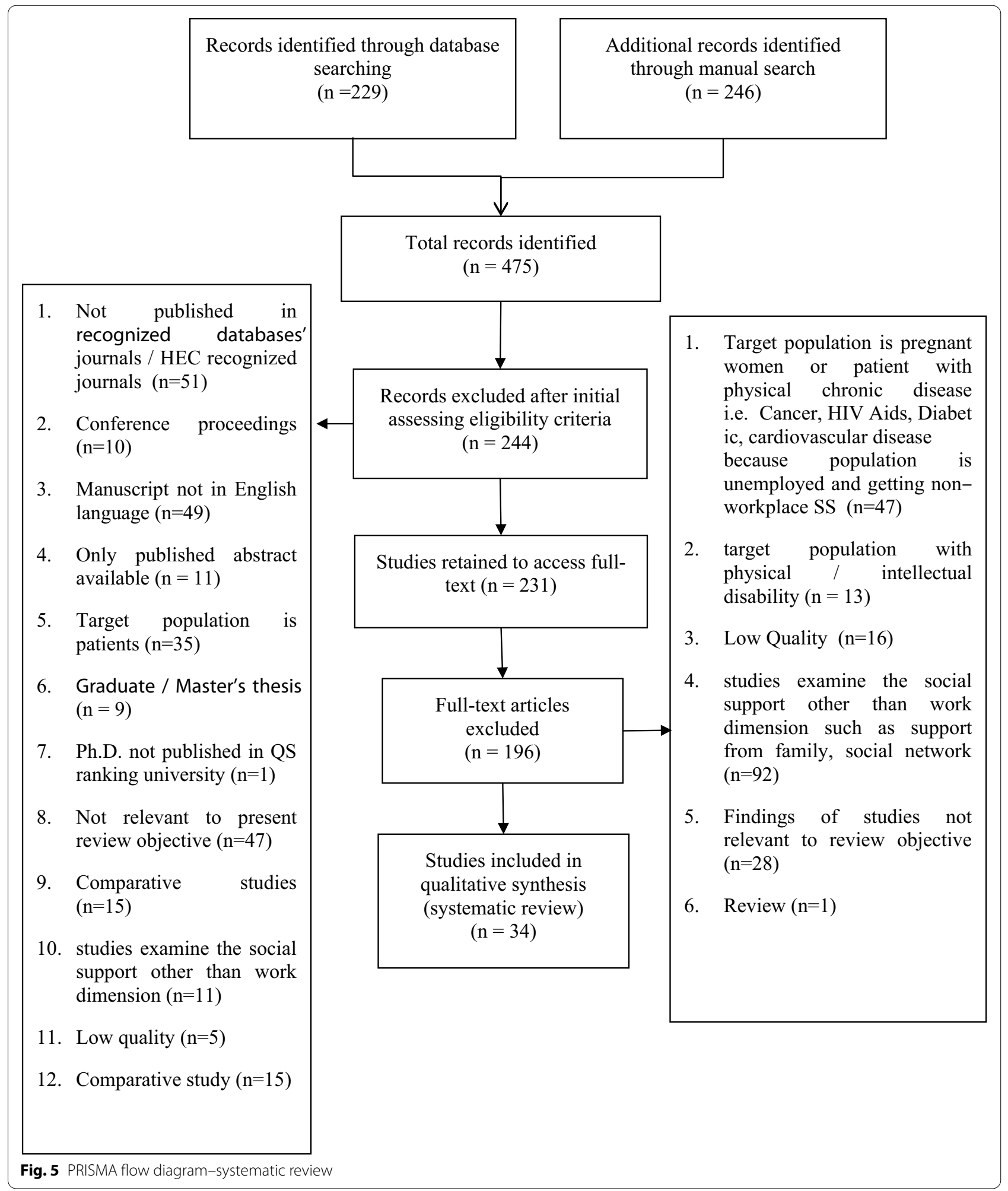

description and tabulation. Detailed characteristics and extracted data of included studies are presented in the table.

\section{Quality assessment}

Quality assessment of all the selected studies is the key phase of systematic review because findings of review depend on it [112]. Quality assessment is a process 
through which the researcher evaluates the strength of the body of evidence and establishes the transparency of findings for systematic review [145]. The quality of all the selected studies has been assessed by using the MMAT critical appraisal tool [61]. This tool/checklist was designed to appraise and describe the methodological quality of five categories of studies, i.e., qualitative, quantitative, mixed-method study, randomized control trials, and non-randomized control trials. According to the evaluation criteria, the researcher required to provide a detailed article for each defined criteria. Studies that were not clear about any of the defined criteria have excluded. In this study, the quality of the selected studies assessed while extracting the data. Overall, 16 studies have been assessed as low quality: detailed quality characteristics of included studies presented in the table.

\section{Analyze and synthesize evidence}

After data extraction, analysis and synthesis are another vital phases of a systematic review. An analysis is a process through which the researcher examines the characteristics of individual studies, identifies its related component, and extracts the possible reasoning [20]. Whereas synthesis is a process that brings together the findings of all the included studies and establishes a knowledge that cannot be interpreted through the findings of individual study [34]. Extracted data are analyzed and examine through narrative synthesis. A narrative synthesis is an approach of systematic review which described as a process of exploring the relationship within and between the studies [8]. Popay et al. [113] identified four key elements for the narrative synthesis process, i.e., developing a theoretical model, developing a preliminary synthesis of findings of included studies, exploring relationships within and between the studies, and assessing the robustness of synthesis. According to the guideline, it is not mandatory to follow these elements sequentially for conducting narrative synthesis. These could be done iteratively.

\section{Narrative review \\ Developing a theoretical model}

The development of a theoretical model for synthesis is referred to as developing the "theory of change" to report the systematic review [113]. It is an element of a systematic review as a whole that defines the objective of the review and it needed to be done before synthesis, and it further contributes while interpreting the review's findings $[8,113]$. By following this guideline, this study described the objective of the systematic review above and in this section focused on three elements of the synthesis process.

\section{Developing a preliminary synthesis of findings of included studies}

This step aimed to conduct an in-depth analysis of retained studies to find out how the association among considered variables has been established and examined in different studies. For this purpose, required information of all the retained studies, extracted with the help of an adapted data extraction form [32] and present through textual description and tabulation.

\section{Assessing the robustness of the synthesis}

This step is referred to as the methodological quality of all the retained primary studies because the strength of synthesis of the literature depends on this step [113]. The trustworthiness of synthesis based on methodologies employed to assess the quality of included and measures that have taken to minimize the bias. As mentioned above, all sequential performance of key elements is not necessary; it can be rearranged according to the study. In the present study, description of inclusion and exclusion and techniques to assess the methodological quality of retained studies is a preliminary step of systematic review before proceeding for synthesis that has been described and done. Therefore, to avoid repetition, this element has not been considered here.

\section{Exploring relationships within and between the studies}

At this phase, the researcher describes how the relationship among the variables has been identified or examines across the studies. One of the basic description and tabulation relationships among variables has been concluded and hypothesized to develop the conceptual framework of the study.

\section{Findings}

In line with the objective of a systematic review synthesis of the literature aimed to develop a conceptual framework for the study by analyzing the role of each identified variable and review their association with each other. From the results and conclusions of retained studies, identified relationship among variable has discussed as follows

\section{Perceived organizational politics, negative affectivity, and psychological wellbeing}

Negative affectivity is the combination of different unstable emotional states such as anxiety, depression, sadness, and unpleasant mood [28, 71, 119]. It is an emotional response to the experience of unpleasant events or the environment. According to affective events theory, employees' experience at the workplace about certain events or environments shapes their attitudes and behavior [149]. Experience depends on perception; employees 
judge and interpret their experience based on perception. Organizational politics is a perceived phenomenon that shapes employees' work-related attitudes and behaviors [1]. As OP is perceived as a negative workplace factor that impacts employees' emotions and negative affectivity has been identified as an outcome emotional state of employees that occurs due to POP [140]. Negative affectivity is strongly predicted by negative experiences and it is highly associated with the individual's physical and psychological health [53]. Perceived organizational politics evokes the negative affectivity that harms the physical and psychological health of employees.

Similarly, employees' psychological wellbeing also depends on their perception and the way they appraise a particular situation [106]. When employees perceive certain situations positively, it enhances their PWB and vice versa. Studies described that psychological wellbeing has a negative association with negative emotions that occurs due to a negative work environment or condition [133]. When employees perceive workplace events negatively, they experience anxiety, depression, and unpleasant emotions that, as a consequence, harm their psychological wellbeing. From the analysis of retained studies, it has identified that perception of OP causes the negative affectivity that, as a result, affects the psychological wellbeing of employees. Negative affectivity channels the negative impact of POP on the psychological wellbeing of employees. Employees' psychological wellbeing is also highly associated with WFC, higher PWB reduces the WFC [2, $3,105]$. Stable PWB enables employees to happily participate in both domains of life, i.e., work and family domain. Employees with deteriorated psychological wellbeing due to work role or negative workplace environment pay less attention to their family role that causes WFC. In light of the above arguments, it can be argued that negative affectivity and psychological wellbeing sequentially mediate the relationship between POP and WFC.

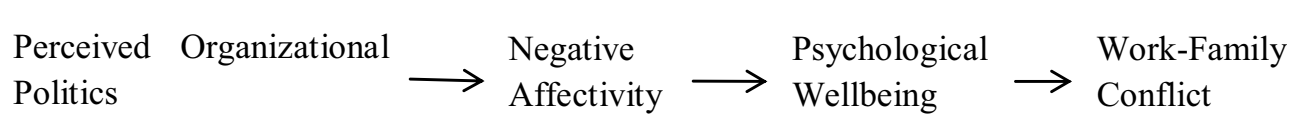

86]. Satisfaction or happiness level of emotionally intelligent employees is high because they can neglect negative emotions and prolong the positive/pleasant state of emotions $[42,56]$. PWB is a pleasant or satisfied state of mind [125]. Emotional intelligence controls the negative affectivity by lowering its symptoms such as aggression and anger [56]. The theory of Salovey and Mayer [124] claims that emotional intelligence positively predicts the PWB of employees because it holds the flow of negative emotions and nourishes optimism [12, 30,33, 127]. The finding of studies has also shown that emotional intelligence moderates the impact of negative emotions that occurs due to negative experience [43, 77]. High emotional intelligence increases the level of PWB by reducing stress, which is a component of negative affectivity [42]. The presence of emotional intelligence enables an individual to overcome adverse effects. It protects and predicts the psychological wellbeing of employees $[5,12,67,93,100$, 123]. Based on the findings of studies, it can be conceptualized that emotional intelligence acts as a moderating variable that alleviates the impact of negative affectivity and safeguards the psychological wellbeing of employees.

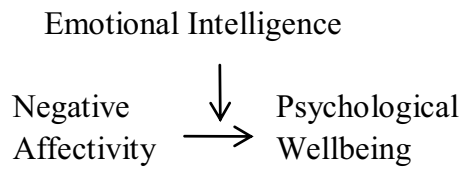

\section{Perceived organizational support, negative affectivity, and psychological wellbeing}

The occurrence of negative affectivity and stability of psychological wellbeing is associated with the cognitive abilities of individuals [84, 143]. Cognitive ability is referred to as individuals' mental capability to perform various psychological activities. A negative experience

\section{Emotional intelligence, negative affectivity, and psychological wellbeing}

Emotional intelligence allows an individual to perceive and interpret certain events and react accordingly correctly. It is highly associated with positive emotion and has an inverse relation with negative affectivity $[13,42$, of employees at the workplace induces negative emotions and interrupts their psychological wellbeing [10]. Nevertheless, their perception that their organization as supportive reduces the occurrence of various negative work-related emotions such as anxiety, depression, and job insecurity, and raise positive feelings within them [24]. When employees sense a particular environment or 
behaviors at the workplace as political and as an unjust that may cause the loss in terms of pay, appraisal, and performance in front accountable authority, it arises the negativity and affects the PWB of employees. However, in the meantime, their perception that the organization is supportive for them, values them, and will never let them suffer from injustice, alleviates the negative consequences of employees' perception about OP and protect PWB [107]. Studies described POS as a cognitive factor that relieves the negative impact of employees' perceptions about OP $[23,36]$. It is positively associated with employees' PWB [103]. Employees' perception of their organization as supportive when they will have conflict at the workplace, it reduces anxiety, depression, and fatigue [92]. POS is an organizational construct that acts positively to enhance the PWB [108, 151]. Findings of retained literature have not highlighted the association between POS and negative affectivity, but from the support of the above-described literature, it can be argued that POS has a moderating impact on the relationship between POP and PWB.

\section{Perceived Organizational Support}

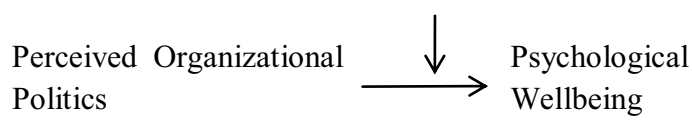

\section{Workplace social support, negative affectivity, and psychological wellbeing}

Emotions and perceptions are psychological factors of individuals that drive their attitudes, behaviors, and actions [65] p.10). Psychological factors refer to the measure that relates psychological phenomena to the social environment [60]. These factors occur and escalate within individuals but have an influencing impact of external factors such as social support [136]. It influences the experience of negative and positive emotions [4]. Individuals having social support experience positive emotions and pleasant mood [15]. The presence of social support mitigates the impact of negative and perception and emotions such as stress [7]. From the findings of studies, it has been identified that social support is positively associated with psychological wellbeing [5, 31, 52, 135]. According to social support theory, the presence of social support reduces the negative impact of stressful events and protects the psychological and physical health of individuals. Perception of OP is itself a workplace stressor that induces negative emotions and affects the PWB of employees. The presence of social support from coworkers at the workplace reduces the negative impact of POP [144]. The literature identified that the workplace social support enhances the PWB of employees [109] and shelters it from the effect of adverse, stressful events, and workplace stressor [105]. This study identified only a single study that denied the importance of emotional intelligence concerning the PWB [13]. In the light of the above arguments, it can also be hypothesized that workplace social support acst as a moderator in such a manner that it reduces the intensity of POP and protects the employees PWB.

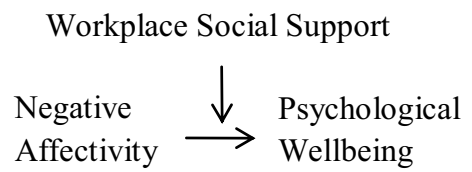

Studies also identified employees with high emotional intelligence are more inclined toward getting social support from the concerned domain $[7,73,74,83]$ to protect the PWB from stress [153].

Based on the above synthesis and hypothesized relationships, the conceptual model for further examination is shown in Fig. 6.

\section{Conclusion}

Perceived organizational politics is known as a critical workplace factor. Existing literature highlighted several insights of POP in which most of the researchers examined and extended the existing model of POP proposed by Ferris and Kacmar [45]. These studies only identified the work-related possible outcomes of POP to understand this phenomenon. This study aimed to examine the existing literature to explain its relationship with a critical non-work-related factor, i.e., WFC.

This study introduced a new insight by systematically combining three literature review approaches to develop a novel conceptual framework. At first, with the help bibliographic co-occurrence network map, this study proved an argument that there are variables that predict the relationship between POP and WFC. But the findings of the bibliographic co-occurrence network map are not enough to identify those specific variables. Therefore, this

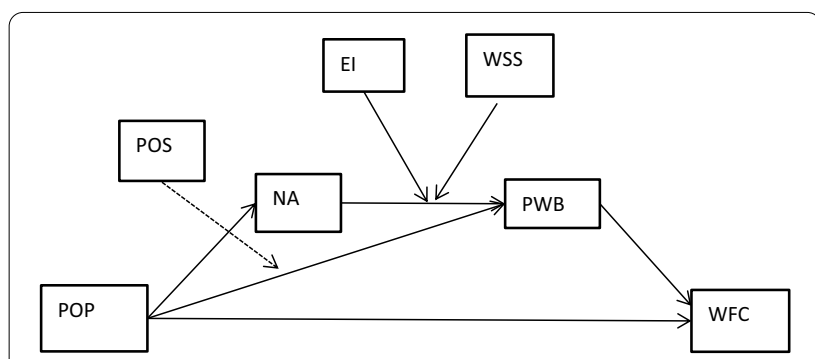

Fig. 6 Conceptual framework 
study is required to conduct a scoping review. Through the scoping review approach, this study comprehensively reviewed all published literature related to antecedents of WFC and outcomes of POP. At first, this study identified the variables that can translate the impact of POP toward WFC. Then through a content analysis, this study further explores and defines those identified variables and also explains the manner through which these variables can logically predict the relationship between POP and WFC. For the variables, no logical literature support was available were ignored. The result of the scoping review revealed five variables that predict the relationship of POP and WFC, i.e., emotional intelligence, negative affectivity, psychological wellbeing, workplace social support, and perceived organizational support. The findings of the scoping review were not sufficient enough to explain how these variables related to each other and form a mechanism through which POP can cause the WFC.

To define the relationship of identified variables with each other and describe how these variables build the relationship of POP and WFC, this study conducted a systematic review. Through this, another comprehensive literature review approach this study proposed hypothesis and formulated a conceptual framework. The findings of the systematic review offered theoretical reasoning to logically define the occurrence of each relationship in the framework. Each identified relation was strongly supported by theories but overall hypothesized mediating mechanism receives support from the conservation of resource (COR) theory. According to theory loss of resources cause stress and harms PWB, employee perceive organizational politics as an unjust behavior at the workplace that can cause loss of resource in term of benefits receiving or will receive at the workplace. This sense of resource due to POP induces negative affectivity in employees [72, 140] that harms their PWB [106]. Due to deteriorated PWB, employees fail to participate in the family domain and experience WFC [101]. Furthermore review also identified that the presence of social support at work, the higher level of emotional intelligence, and perception about the organization as supportive eliminate the spillover of POP toward WFC.

The findings of this study articulated a new area of inquiry in the field of organizational behavior. It also provided new insight for conducting systematic review by systematically combining three approaches to answer the research objective. This is the first study that assesses the relationship between POP and WFC based on scoping and systematic review and presented a new framework by reviewing all the previous research. This research approach may be adopted for conducting a systematic review according to the research objective. Furthermore, the findings of this study are relevant enough to consider a new area for future research. This model can empirically examine to assess the validity and predictive power of the model and also find that if the proposed relationships are consistent over time.

\section{Abbreviations}

COR: conservation of resource; DCF: data charting form; El: emotional intelligence; MA: microsoft academy; NA: negative affectivity; OCB: organizational citizenship behavior; OP: organizational politics; POP: perceived organizational politics; POS: perceived organizational support; PWB: psychological wellbeing; WFC: work-to-family conflict; WSS: workplace social support.

\section{Acknowledgements}

First and foremost, all praise to Almighty Allah, the most gracious and the most merciful for the blessing, wisdom health, and strength to carry out this exciting and challenging M.Phill. journey. I would like to express my profound gratitude to my supervisor for his kind support, supervision, and guidance throughout this journey. I am thankful to him for helping me. Also, I wish to thank my beloved Mother and my dearest Sister for their encouragement, continuous support, and prayers.

\section{Authors' contributions}

Ms. SF carried out this research as a first author, Dr. MAQ supported the research as a supervisor. All authors have read and approved the manuscript.

Funding

No funding received for this research.

\section{Availability of data and materials}

The data that support the findings of this study are available at would be provided upon request.

\section{Data availability}

The data sets generated during and/or analyzed during the current study are available from the corresponding author on reasonable request.

\section{Compliance with ethical standards}

\section{Competing interests}

The authors declare that they have no competing interests.

\section{Ethical approval}

All procedures performed in studies were in accordance with the ethical standards of the institutional research committee (Dr. Adnan Bashir, adnan. bashir@iobm.edu.pk) and with the 1964 Helsinki Declaration and its later amendments or comparable ethical standards."

Received: 20 July 2020 Accepted: 19 November 2020 Published: 12 January 2021

\footnotetext{
References

1. Abbas HW, Shafique M, Qadeer PF, Moinud Din N, Ahmad R, Saleem S (2015) Impact of perceptions of organizational politics on employees' job outcomes: the moderating role of self-efficacy and personal political skills (SSRN Scholarly Paper ID 2631403). Social Science Research Network. https://papers.ssrn.com/abstract $=2631403$

2. Adalikwu C (2014) Demographic predictors of work-family conflict for men and women: the case of Nigeria. Res Bus Manag 1(1):29-50

3. Aggarwal-Gupta M, Vatharkar P (2017) Impact of stress and work-family conflict on the mental well-being of physicians: mediation by job and career satisfaction. Br J Healthc Manag 23(9):409-416

4. Ahmed W, Minnaert A, van der Werf G, Kuyper H (2008) Perceived social support and early adolescents' achievement: the mediational roles of motivational beliefs and emotions. J Youth Adolesc 39(1):36. https://doi. org/10.1007/s10964-008-9367-7
} 
5. Akhtar MW, Ghufran H, Fatima T (2017) The effect of emotional intelligence on turnover intentions; The role of employee well-being, engagement and perceived organisational support. Jinnah Bus Rev 5(2):69-80

6. Allen TD, French KA, Dumani S, Shockley KM (2015) Meta-analysis of work-family conflict mean differences: does national context matter? J Vocat Behav 90:90-100. https://doi.org/10.1016/j.jvb.2015.07.006

7. Aloia LS, Brecht D (2017) Psychological well-being as a function of affectionate communication and emotional intelligence. Commun Res Rep 34(4):297-306. https://doi.org/10.1080/08824096.2017.1350570

8. Arai L, Britten N, Popay J, Roberts H, Petticrew M, Rodgers M, Sowden A (2007) Testing methodological developments in the conduct of narrative synthesis: a demonstration review of research on the implementation of smoke alarm interventions. Evid Policy: A J Res Debate Pract 3(3):361-383. https://doi.org/10.1332/174426407781738029

9. Ashforth BE, Kreiner GE, Fugate M (2000) All in a day's work: boundaries and micro role transitions. Acad Manag Rev 25(3):472-491

10. Ashkanasy NM, Dorris A (2017) Emotions in the Workplace (SSRN Scholarly Paper ID 2947675). Social Science Research Network. https://paper s.ssrn.com/abstract $=2947675$

11. Atta M, Khan MJ (2016) Perceived organizational politics, organizational citizenship behavior and job attitudes among university teachers. J Behav Sci 26(2):21-38

12. Augusto Landa JM, Martos MP, López-Zafra E (2010) Emotional Intelligence and Personality Traits as Predictors of Psychological WellBeing in Spanish Undergraduates [Text]. https://doi.org/10.2224/ sbp.2010.38.6.783

13. Avsec $A$, Masnec $P$, Komidar $L$ (2009) Personality traits and emotional intelligence as predictors of teachers' psychological well-being. Psihološka Obzorja/Horizons Psychol 18(3):73-86

14. Badawy P, Schieman S (2020) Control and the health effects of work-family conflict: a longitudinal test of generalized versus specific stress buffering. J Health Soc Behav 61 (3):324-341. https://doi. org/10.1177/0022146520942897

15. Baumeister RF, Leary MR (1995) The need to belong: desire for interpersonal attachments as a fundamental human motivation. Psychol Bull 117(3):497-529. https://doi.org/10.1037/0033-2909.117.3.497

16. Bedi A, Schat ACH (2013) Perceptions of organizational politics: a metaanalysis of its attitudinal, health, and behavioural consequences. Can Psychol 54(4):246-259. https://doi.org/10.1037/a0034549

17. Bergeron DM, Thompson PS (2020) Speaking up at work: the role of perceived organizational support in explaining the relationship between perceptions of organizational politics and voice behavior. J Appl Behav Sci. https://doi.org/10.1177/0021886319900332

18. Bodla MA, Danish RQ (2009) Politics and workplace: an empirical examination of the relationship between perceived organizational politics and work performance. South Asian J Manag 16(1):44-62

19. Bornmann L, Haunschild R, Hug SE (2018) Visualizing the context of citations referencing papers published by Eugene Garfield: a new type of keyword co-occurrence analysis. Scientometrics 114(2):427-437. https://doi.org/10.1007/s11192-017-2591-8

20. Briner RB, Denyer D (2012) Systematic review and evidence synthesis as a practice and scholarship tool. Oxford University Press, Oxford. https:// doi.org/10.1093/oxfordhb/9780199763986.013.0007

21. Bronfenbrenner U, Morris PA (1998) The ecology of developmental processes. In: Handbook of child psychology: theoretical models of human development, vol 1, 5th edn. Wiley, pp 993-1028

22. Brouer RL, Ferris GR, Hochwarter WA, Laird MD, Gilmore DC (2006) The strain-related reactions to perceptions of organizational politics as a workplace stressor: political skill as a neutralizer. Handbook of Organizational Politics 187:206

23. Bukhari I, Kamal A (2015) Relationship between perceived organizational politics and its negative outcomes: moderating role of perceived organizational support. Pak J Psychol Res 30(2):271

24. Bukhari I, Kamal A (2017) Perceived organizational support, its behavioral and attitudinal work outcomes: moderating role of perceived organizational politics. Pak J Psychol Res 32(2):581-602

25. Burke RJ, Greenglass ER (2001) Hospital restructuring, work-family conflict and psychological burnout among nursing staff. Psychol Health 16(5):583-594
26. Byrne ZS (2005) Fairness reduces the negative effects of organizational politics on turnover intentions, citizenship behavior and job performance. J Bus Psychol. https://doi.org/10.1007/s10869-005-8258-0

27. Byron K (2005) A meta-analytic review of work-family conflict and its antecedents. JVocat Behav. https://doi.org/10.1016/j.jvb.2004.08.009

28. Carmody JF, Baer RA, Lykins ELB, Olendzki N (2009) An empirical study of the mechanisms of mindfulness in a mindfulness-based stress reduction program. J Clin Psychol 65(6):613-626. https://doi.org/10.1002/ jclp.20579

29. Chang C-H, Rosen CC, Levy PE (2009) The relationship between perceptions of organizational politics and employee attitudes, strain, and behavior: a meta-analytic examination. Acad Manag J 52(4):779-801. https://doi.org/10.5465/amj.2009.43670894

30. Chauhan AS, Joshi GR (2013) Relationship between emotional intelligence and psychological well being among police personnel. Indian J Positive Psychol 4(1):115. https://www.questia.com/library/journal/1P33466318001/relationship-between-emotional-intelligence-and-psych ological

31. Cho S (2019) Effects of social support and grateful disposition on employees' psychological well-being. Serv Ind J 39(11-12):799-819. https://doi.org/10.1080/02642069.2018.1444755

32. Ryan R, Synnot A, Prictor M, Hill S (2018) Cochrane consumers and communication La Trobe University. Data Extraction Template. https://doi. org/10.26181/5b57cfd711743

33. Costa H, Ripoll P, Sánchez M, Carvalho C (2013) Emotional intelligence and self-efficacy: effects on psychological well-being in college students. Spanish Journal of Psychology. https://doi.org/10.1017/ s.jp.2013.39

34. Denyer D, Tranfield D (2009) Producing a systematic review. The Sage handbook of organizational research methods

35. Dierdorff EC, Ellington JK (2008) It's the nature of the work: examining behavior-based sources of work-family conflict across occupations. J Appl Psychol 93(4):883

36. Donald MF, Bertha L, Lucia ME (2016) Perceived organzational politics influences on organizational commitment among supporting staff members at a selected higher education institution. The 2016 Wei International Academic Conference Proceedings, Vienna, Austria

37. Drory A, Meisler G (2016) 13 Emotion and emotional intelligence in organizational politics. Handbook of organizational politics: looking back and to the future, 319

38. Drory A, Romm T (1988) Politics in organization and its perception within the organization. Organ Stud 9(2):165-179

39. Eisenberger R, Huntington R, Hutchison S, Sowa D (1986) Perceived organizational support. J Appl Psychol 71(3):500

40. Eisenberger R, Armeli S, Rexwinkel B, Lynch P, Rhoades L (2001) Reciprocation of perceived organizational support. J Appl Psychol 86(1):42-51. insights.ovid.com

41. Epitropaki O, Kapoutsis I, Ellen BP, Ferris GR, Drivas K, Ntotsi A (2016) Navigating uneven terrain: the roles of political skill and LMX differentiation in prediction of work relationship quality and work outcomes: LMX Differentiation and Political Skill. J Organ Behav 37(7):1078-1103. https://doi.org/10.1002/job.2100

42. Extremera N, Rey L (2016) Ability emotional intelligence and life satisfaction: positive and negative affect as mediators. Personal Individ Differ 102:98-101. https://doi.org/10.1016/.jpaid.2016.06.051

43. Fazio J (2015) The interaction of perceived organizational support and emotional intelligence: Mediated moderated effects on work outcomes_ProQuest [Nova Southeastern University]. https://search.proqu est.com/openview/28f8cb808134c3d6ac66c34d175524a2/1?pq-origs ite $=$ gscholar \&cbl $=18750 \&$ diss $=y$

44. Ferris GR, Adams G, Kolodinsky RW, Hochwarter WA, Ammeter AP (2002). Perceptions of organizational politics: theory and research directions. In: Research in multi level issues. Emerald (MCB UP), vol 1, pp 179-254. https://doi.org/10.1016/S1475-9144(02)01034-2

45. Ferris GR, Kacmar KM (1992) Perception of organizational politics. J Manag 18(1):93-116. https://www.researchgate.net/profile/K_Kacmar/ publication/247569609_Perceptions_of_Organizational_Politics/links 1544a34ea0cf244fe9ea6379e.pdf

46. Fiksenbaum LM (2013) Burning the candle at both ends: an examination of the antecedents and consequences of work-family conflict. ProQuest Information \& Learning 
47. Ford MT, Heinen BA, Langkamer KL (2007) Work and family satisfaction and conflict: a meta-analysis of cross-domain relations. J Appl Psychol 92(1):57-80. https://doi.org/10.1037/0021-9010.92.1.57

48. Fredrickson BL, Joiner T (2002) Positive emotions trigger upward spirals toward emotional well-being. Psychol Sci 13(2):172-175. JSTOR. https:// www.jstor.org/stable/40063861

49. French KA, Dumani S, Allen TD, Shockley KM (2018) A meta-analysis of work-family conflict and social support. Psychol Bull 144(3):284-314. https://doi.org/10.1037/bul0000120

50. Furlan AD, Pennick V, Bombardier C, van Tulder M, Group, from the E. B. of the C. B. R. (2009) Updated method guidelines for systematic reviews in the cochrane back review group. Spine 34(18):1929. https://doi. org/10.1097/BRS.0b013e3181b1c99f

51. Gandz J, Murray VV (1980) The experience of workplace politics. Acad Manag J 23(2):237-251

52. Gençöz T, Özlale Y, Lennon R (2004) Direct and indirect effects of socia support on psychological well-being [Text]. https://doi.org/10.2224/ sbp.2004.32.5.449

53. Goh YW, Sawang S, Oei TPS (2010) The revised transactional model (RTM) of occupational stress and coping: an improved process approach. Austral J Organ Psychol 3:13-20. https://doi.org/10.1375/ ajop.3.1.13

54. Greenhaus JH, Beutell NJ (1985) Sources of conflict between work and family roles. Acad Manag Rev 10(1):76-88

55. Gurbuz S, Turunc O, Celik M (2013) The impact of perceived organizational support on work-family conflict: does role overload have a mediating role? Econ Ind Democr 34(1):145-160

56. Gutiérrez-Cobo MJ, Megías A, Gómez-Leal R, Cabello R, Fernández-Berrocal $P$ (2018) The role of emotional intelligence and negative affect as protective and risk factors of aggressive behavior: a moderated mediation model. Aggress Behav 44(6):638-646. https://doi.org/10.1002/ ab.21788

57. Hammer GB, Bodner T, Zimmerman RK, Anger WK, Kossek EE (2010) Clarifying work-family intervention processes: the roles of work-family conflict and family-supportive supervisor behaviors. J Appl Psychol. https://doi.org/10.1037/a0020927

58. Hanif MI, Waheed N, Hamid ABA, Mahmood Z (2018) The impact of organizational politics on job satisfaction \& organizational commitment: moderating role of perceived social support. Pak J Soc Sci 38(2):551-565

59. Hargis MB, Kotrba LM, Zhdanova L, Baltes BB (2011) What's really important? Examining the relative importance of antecedents to work-family conflict. J Manag Issues 23:386-408

60. Hemingway H, Marmot M (1999) Psychosocial factors in the aetiology and prognosis of coronary heart disease: systematic review of prospective cohort studies. BMJ 318(7196):1460-1467. https://doi.org/10.1136/ bmj.318.7196.1460

61. Hong QN, Fàbregues S, Bartlett G, Boardman F, Cargo M, Dagenais P, Gagnon M-P, Griffiths F, Nicolau B, O'Cathain A, Rousseau M-C, Vedel I, Pluye P (2018) The Mixed Methods Appraisal Tool (MMAT) version 2018 for information professionals and researchers. Educ Inf 34(4):285-291. https://doi.org/10.3233/EFl-180221

62. Houben M, Van W, Noortgate D (2015) The relation between short-term emotion dynamics and psychological well-being: a meta-analysis, vol 141. American Psychological Association

63. Hummayon AA, Shahid MR, Khan MA (2019) Effects of organizational politics on job performance: mediating role of emotional intelligence and organizational commitment. Politics 3(1):2019

64. Ilies R, Schwind KM, Wagner DT, Johnson MD, DeRue DS, Ilgen DR (2007) When can employees have a family life? The effects of daily workload and affect on work-family conflict and social behaviors at home. J Appl Psychol 92(5):1368-1379. https://doi. org/10.1037/0021-9010.92.5.1368

65. Izard CE (2013) Human emotions. Springer, Berlin

66. Jaga A (2014) Antecedents of work-family conflict among Hindu working women in South Africa: stressors, social support, and cultural values. PhD Thesis. University of Cape Town

67. James C, Bore M, Zito S (2012) Emotional intelligence and personality as predictors of psychological well-being. J Psychoeduc Assess 30(4):425-438. https://doi.org/10.1177/0734282912449448
68. Jensen JM, van de Voorde K (2015) High-performance work systems and employee health/well-being: burnout, thriving, and work engagement. Acad Manag Proc 2015(1):12742. https://doi.org/10.5465/ambpp .2015.12742symposium

69. Juniarly A, Purnamasari A, Anggraini D, Andini H (2019) Emotional intelligence, subjective wellbeing, and work-family conflict among University Lecturers. ANIMA Indones Psychol J 33(4):1. https://doi. org/10.24123/aipj.v33i4.1798

70. Kacmar KM, Bozeman DP, Carlson DS, Anthony WP (1999) An examination of the perception of organizational politics model: replication and extension. Hum Relat 52(3):383. https://www.researchgate.net/profi le/K_Kacmar/publication/247717383_An_Examination_of_the_Perce ptions_of_Organizational_Politics_Model_Replication_and_Extension/ links/543be9f10cf2d6698be35077.pdf

71. Keng S-L, Smoski MJ, Robins CJ (2011) Effects of mindfulness on psychological health: a review of empirical studies. Clin Psychol Rev 31(6):1041-1056. https://doi.org/10.1016/j.cpr.2011.04.006

72. Kiewitz C, Restubog SLD, Zagenczyk T, Hochwarter W (2009) The interactive effects of psychological contract breach and organizational politics on perceived organizational support: evidence from two longitudinal studies. J Manag Stud 46(5):806-834

73. Kong F, Gong X, Sajjad S, Yang K, Zhao J (2019) How is emotional intelligence linked to life satisfaction? The mediating role of social support, positive affect and negative affect. J Happiness Stud 20(8):2733-2745. https://doi.org/10.1007/s10902-018-00069-4

74. Kong F, Zhao J, You X (2012) Emotional intelligence and life satisfaction in Chinese university students: the mediating role of self-esteem and social support. Personal Individ Differ 53(8):1039-1043. https://doi. org/10.1016/j.paid.2012.07.032

75. Kossek EE, Pichler S, Bodner T, Hammer LB (2011) Workplace social support and work-family conflict: a meta-analysis clarifying the influence of general and work-family-specific supervisor and organizational support. Pers Psychol 64(2):289-313

76. Kurtessis JN, Eisenberger R, Ford MT, Buffardi LC, Stewart KA, Adis CS (2017) Perceived organizational support: a meta-analytic evaluation of organizational support theory. J Manag 43(6):1854-1884. https://doi. org/10.1177/0149206315575554

77. Swain AL (2019) The relationship between managers' emotional intelligence, positive and negative affect, and employee voice-ProQuest [The Chicago School of Professional Psychology]. https://search.proqu est.com/openview/958492357d71e524d4f62b9dc914548b/1?pq-origs ite $=$ gscholar $\& \mathrm{cbl}=18750 \&$ diss $=y$

78. Labrague L, McEnroe-Petitte DM, Gloe D, Tsaras K, Arteche DL, Maldia F (2017) Organizational politics, nurses'stress, burnout levels, turnover intention and job satisfaction. Int Nurs Rev 64(1):109-116. https://doi. org/10.1111/inr.12347

79. Landells EM, Albrecht SL (2017) The Positives and negatives of organizational politics: a qualitative study. J Bus Psychol 32(1):41-58. https://doi. org/10.1007/s10869-015-9434-5

80. Landells EM, Albrecht SL (2019) Perceived organizational politics, engagement and stress: the mediating influence of meaningful work. Front Psychol 10:1612

81. Lenaghan JA, Buda R, Eisner AB (2007) An examination of the role of emotional intelligence in work and family conflict. J Manag Issues 19(1):76-94. JSTOR. https://www.jstor.org/stable/40601194

82. Levac D, Colquhoun H, O'Brien KK (2010) Scoping studies: advancing the methodology. Implement Sci 5(1):1-9. https://doi. org/10.1186/1748-5908-5-69

83. Liu D (2018) Mediating effect of social support between the emotional intelligence and job satisfaction of Chinese employees. Curr Psychol 37(1):366-372. https://doi.org/10.1007/s12144-016-9520-5

84. Llewellyn DJ, Lang IA, Langa KM, Huppert FA (2008) Cognitive function and psychological well-being: findings from a population-based cohort. Age Ageing 37(6):685-689. https://doi.org/10.1093/ageing/ afn194

85. LodahI TM, Kejnar M (1965) The definition and measurement of job involvement. J Appl Psychol 49(1):24-33. https://doi.org/10.1037/h0021 692

86. Loi NM, Golledge C (2018) The role of positive and negative affect in the relationship between emotional intelligence and uncivil workplace 
behaviour among managers [Poster]. https://rune.une.edu.au/web/ handle/1959.11/27032

87. Lowe D, Levitt KJ, Wilson T (2008) Solutions for retaining generation Y employees in the workplace. Bus Renaiss Q 3(3):43-58

88. Lu C-C, Ting Y-S, Hsu Y-L (2016) The review of work and family balance among employees in hospitality industry in Taiwan. Int Bus Res 9(9):51-57. https://ideas.repec.org/a/ibn/ibrjnl/v9y2016i9p51-57.html

89. Luqman MK, Javaid MF, Umair T (2015) Combined effects of perceived organizational politics and emotional intelligence on job satisfaction and counterproductive work behaviors. Eur Online J Nat Soc Sci 4(4):891

90. Madison DL, Allen RW, Porter LW, Renwick PA, Mayes BT (1980) Organizational politics: an exploration of managers' perceptions. Hum Relat 33(2):79-100

91. Makhdoom IF, Mehmood B, Atta M (2017) Mediating role of job burnout for the relationship of perceived organizational politics and counterproductive work behaviors among school teachers. J Behav Sci 27(2):149-164

92. Marchand C, Vandenberghe C (2015) Perceived organizational support, perceived resource loss, and psychological health: the moderating effect of negative affectivity. Le Travail Humain 78(3):193-216. https:// www.cairn-int.info/revue-le-travail-humain-2015-3-p-193.htm

93. Marikutty PJ, Joseph MI (2016) Effects of emotional intelligence on stress, psychological well-being, and academic achievement of adolescents_-ProQuest. Indian J Health Wellbeing 7(7):699-702. https:// search.proquest.com/openview/75c14e32c74152559d834c03cedecd $4 \mathrm{a} / 1$ ? pq-origsite $=$ gscholar\&cbl $=2032134$

94. Maslach C, Leiter MP (2016) Burnout. In: Stress: concepts, cognition, emotion, and behavior. Elsevier, pp 351-357. https://doi.org/10.1016/ B978-0-12-800951-2.00044-3

95. Matsui T, Ohsawa T, Onglatco M-L (1995) Work-family conflict and the stress-buffering effects of husband support and coping behavior among japanese married working women. J Vocat Behav 47(2):178192. https://doi.org/10.1006/jvbe.1995.1034

96. Matta FK, Erol-Korkmaz HT, Johnson RE, Biçaksiz P (2014) Significant work events and counterproductive work behavior: the role of fairness, emotions, and emotion regulation. J Organ Behav 35(7):920-944. https ://doi.org/10.1002/job.1934

97. Mayer JD, Caruso DR, Salovey P (2000) Emotional intelligence meets traditional standards for an intelligence. Intelligence 27(4):267-298. http://www.gruberpeplab.com/teaching/psych3131_spring2015/ documents/13.2_Mayer_2000_EmotionIntelligenceMeetsStandardsFo rTraditionallntelligence.pdf

98. Mayer JD, Salovey P, Caruso DR (2004) Emotional intelligence: theory, findings, and implication. Psychol Inquiry 15(3):197-215. http://www. calcasa.org/wp-content/uploads/files/ei2004mayersaloveycarusotarget .pdf

99. Michel JS, Kotrba LM, Mitchelson JK, Clark MA, Baltes BB (2011) Antecedents of work-family conflict: a meta-analytic review. J Organ Behav 32(5):689-725. https://doi.org/10.1002/job.695

100. Montes-Berges B, Augusto-Landa J-M (2014) Emotional intelligence and affective intensity as life satisfaction and psychological well-being predictors on nursing professionals. J Prof Nurs 30(1):80-88. https://doi. org/10.1016/j.profnurs.2012.12.012

101. Neto M, Chambel MJ, Carvalho VS (2018) Work-family life conflict and mental well-being. Occup Med 68(6):364-369. https://doi.org/10.1093/ occmed/kqy079

102. Ngnoumen CT, Langer EJ, Langer EJ (2016) Mindfulness: the essence of well-being and happiness. Mindfulness in Positive Psychology. https:// doi.org/10.4324/9781315747217-13

103. Ni C, Wang Y (2015) The impact of perceived organizational support and core self-evaluation on employee's psychological well-being. J Hum Resour Sustain Stud 03(02):73. https://doi.org/10.4236/jhrss .2015 .32011

104. Nilsen W, Skipstein A, Demerouti E (2016) Adverse trajectories of mental health problems predict subsequent burnout and work-family conflict-a longitudinal study of employed women with children followed over 18 years. BMC Psychiatry. https://doi.org/10.1186/s1288 8-016-1110-4

105. O'Driscoll MP, Brough P, Kalliath TJ (2004) Work/family conflict, psychological well-being, satisfaction and social support: a longitudinal study in New Zealand. Equal Oppor Int 23(1/2):36-56. https://doi. org/10.1108/02610150410787846

106. Oliver J, Brough P (2002) Cognitive appraisal, negative affectivity and psychological well-being. N Z J Psychol 31(1):2-7

107. Pahlevan Sharif S (2017) Locus of control, quality of life, anxiety, and depression among Malaysian breast cancer patients: the mediating role of uncertainty. Eur J Oncol Nurs 27:28-35. https://doi.org/10.1016/j. ejon.2017.01.005

108. Panaccio A, Vandenberghe C (2009) Perceived organizational support, organizational commitment and psychological well-being: a longitudinal study. J Vocat Behav 75(2):224-236. https://doi.org/10.1016/j. jvb.2009.06.002

109. Pears J (2004). Evaluating the influence of the type of social support on job satisfaction and work related psychological well-being. Int J Organ Behav 8(2):475-485. https://core.ac.uk/reader/143875170

110. Pines AM (2017) Burnout: an existential perspective. Professional Burnout. https://doi.org/10.4324/9781315227979-4

111. Poggesi S, Mari M, De Vita L (2019) Women entrepreneurs and workfamily conflict: an analysis of the antecedents. Int Entrep Manag J 15(2):431-454. https://doi.org/10.1007/s11365-017-0484-1

112. Pollock A, Berge E (2018) How to do a systematic review. Int I Stroke 13(2):138-156. https://doi.org/10.1177/1747493017743796

113. Popay J, Roberts H, Sowden A, Petticrew M, Arai L, Rodgers M, Britten N, Roen K, Duffy S (2006) Guidance on the conduct of narrative synthesis in systematic reviews: a product from the ESRC Methods Programme. Lancaster University. https://doi.org/10.13140/2.1.1018.4643

114. Price R (2019) The politics of organizational change. Routledge, New York. https://doi.org/10.4324/9780429467950

115. Prinsen CAC, Mokkink LB, Bouter LM, Alonso J, Patrick DL, de Vet HCW, Terwee CB (2018) COSMIN guideline for systematic reviews of patientreported outcome measures. Qual Life Res 27(5):1147-1157. https://doi. org/10.1007/s11136-018-1798-3

116. Rabinowitz S, Hall DT (1977) Organizational research on job involvement. Psychol Bull 84(2):265-288. https://doi. org/10.1037/0033-2909.84.2.265

117. Ram P, Prabhakar GV (2010) Leadership styles and perceived organizational politics as predictors of work related outcomes. Eur J Soc Sci 15(1):40-55

118. Rhoades L, Eisenberger R (2002) Perceived organizational support: a review of the literature. J Appl Psychol 87(4):698-714. insights.ovid.com

119. Ridner SH (2004) Psychological distress: concept analysis. J Adv Nurs 45(5):536-545. https://doi.org/10.1046/j.1365-2648.2003.02938.x

120. Robinson LD (2017) The work-family interface and burnout in sole and partnered working Australian mothers. Doctor of Philosophy thesis, School of Psychology, University of Wollongong, 2017. https://ro.uow. edu.au/theses $1 / 69$

121. Rong Z, Cao G (2015) A framework for research and practice: relationship among perception of organizational politics, perceived organization support, organizational commitment and work engagements. Open J Bus Manag 3(04):433

122. Ros-Morente A, Alsinet Mora C, Torrelles Nadal C, Blasco Belled A, Jordana Berenguer N (2017) An examination of the relationship between emotional intelligence, positive affect and character strengths and virtues. Anal Psicol 34(1):63. https://doi.org/10.6018/analesps.34.1.262891

123. Salami SO (2011) Personality and psychological well-being of adolescents: the moderating role of emotional intelligence. Soc Behav Pers 39(6):785-794. https://doi.org/10.2224/sbp.2011.39.6.785

124. Salovey P, Mayer JD (1990) Emotional intelligence. Imagination Cogn Personal 9(3):185-211

125. Schmutte PS, Ryff CD (1997) Personality and well-being: reexamining methods and meanings. J Pers Soc Psychol 73(3):549-559. https://doi. org/10.1037/0022-3514.73.3.549

126. Schumer MC, Lindsay EK, Creswell JD (2018) Brief mindfulness training for negative affectivity: a systematic review and meta-analysis. J Consult Clin Psychol 86(7):569-583. https://doi.org/10.1037/ccp0000324

127. Shah SAA, Yezhuang T, Shah AM, Durrani DK, Shah SJ (2018) Fear of terror and psychological well-being: the moderating role of emotional intelligence. Int J Environ Res Public Health 15(11):2554. https://doi. org/10.3390/ijerph15112554

128. Silva KT (2018) Employee reactions to perceived political motives in performance appraisal (Doctoral dissertation) 
129. Smith TD, Hughes K, DeJoy DM, Dyal M-A (2018) Assessment of relationships between work stress, work-family conflict, burnout and firefighter safety behavior outcomes. Saf Sci 103:287-292. https://doi. org/10.1016/j.ssci.2017.12.005

130. Snipes RL, Pitts J (2013) Politics in the workplace: an empirical examination of the relationship between gender, perceived organizational politics, and job satisfaction. In: Proceedings of the allied academies international conference. Academy of organizational culture, communications and conflict, vol 18, p 27

131. Sowmya KR, Panchanatham N (2016) Relationship between employees' perception of organizational politics and emotional intelligence. In: Proceedings of international HR conference, vol 3

132. Stoeva AZ, Chiu RK, Greenhaus JH (2002) Negative affectivity, role stress, and work-family conflict. J Vocat Behav 60(1):1-16

133. Suleman Q, Hussain I, Shehzad S, Syed MA, Raja SA (2018) Relationship between perceived occupational stress and psychological well-being among secondary school heads in Khyber Pakhtunkhwa, Pakistan. PLoS ONE 13(12):e0208143. https://doi.org/10.1371/journal.pone.0208143

134. Tetteh SD (2016) Social capital, perceived organizational politics, and workplace crime: a study of workers at the driver and vehicle licensing authority in the Eastern and Greater Accra Regions Of Ghana [PhD Thesis]. University of Ghana

135. Thoits PA (1985) Social support and psychological well-being: theoretical possibilities. In: Sarason IG, Sarason BR (eds) Social support: theory, research and applications. Springer Netherlands, Dordrecht, pp 51-72. https://doi.org/10.1007/978-94-009-5115-0_4

136. Thoits PA (2011) Mechanisms linking social ties and support to physical and mental health. J Health Soc Behav 52(2):145-161. https://doi. org/10.1177/0022146510395592

137. Tov W, Diener E (2013) Subjective wellbeing. In: Keith KD (ed) The encyclopedia of cross-cultural psychology. Wiley, New York, pp 1239-1245. https://doi.org/10.1002/9781118339893.wbeccp518

138. Tremblay D-G, Paquet R, Najem E (2006) Telework: a way to balance work and family or an increase in work-family conflict? Can J Commun 31(3):715-731

139. Uchino BN, Bowen K, Kent de Grey R, Mikel J, Fisher EB (2018) Social support and physical health: models, mechanisms, and opportunities. In: Fisher EB, Cameron LD, Christensen AJ, Ehlert U, Guo Y, Oldenburg B, Snoek FJ (eds) Principles and concepts of behavioral medicine: a global handbook. Springer, Berlin, pp 341-372. https://doi.org/10.1007/978-0387-93826-4_12

140. Valle M, Witt LA, Hochwarter WA (2002) Dispositions and organizational politics perceptions: the influence of positive and negative affectivity. J Manag Res 2(3):121

141. Van Cappellen P, Toth-Gauthier M, Saroglou V, Fredrickson BL (2016) Religion and well-being: the mediating role of positive emotions. J Happiness Stud 17(2):485-505. https://doi.org/10.1007/s10902-014-9605-5

142. van Eck NJ, Waltman $L$ (2011) Text mining and visualization using VOSviewer. http://arxiv.org/abs/1109.2058

143. Vassend O, Watten R, Myhrer T, Syvertsen JL (1994) Negative affectivity and intellectual ability: a study of their relation to self-reported physical symptoms, perceived daily stress and mood, and disciplinary problems in military recruits. Soc Sci Med 39(4):583-590. https://doi. org/10.1016/0277-9536(94)90101-5

144. Vigoda-Gadot E, Talmud I (2010) Organizational politics and job outcomes: the moderating effect of trust and social support: organizational politics and job outcomes. J Appl Soc Psychol 40(11):2829-2861. https://doi.org/10.1111/j.1559-1816.2010.00683.x

145. Viswanathan M, Ansari MT, Berkman ND, Chang S, Hartling L, McPheeters M, Santaguida PL, Shamliyan T, Singh K, Tsertsvadze A, Treadwell JR (2008) Assessing the risk of bias of individual studies in systematic reviews of health care interventions. In: Methods guide for effectiveness and comparative effectiveness reviews. Agency for Healthcare Research and Quality (US). http://www.ncbi.nlm.nih.gov/ books/NBK91433/

146. Waltman L, van Eck NJ, van Leeuwen TN, Visser MS, van Raan AFJ (2011) Towards a new crown indicator: some theoretical considerations. J Informetr 5(1):37-47. https://doi.org/10.1016/j.joi.2010.08.001

147. Watson D, Clark LA (1984) Negative affectivity: the disposition to experience aversive emotional states. Psychol Bull 96(3):465-490. https://doi. org/10.1037/0033-2909.96.3.465

148. Watson D, Clark LA, Carey G (1988) Positive and negative affectivity and their relation to anxiety and depressive disorders. J Abnorm Psychol 97(3):346-353. https://doi.org/10.1037/0021-843X.97.3.346

149. Weiss HM, Cropanzano R (1996) Affective events theory: a theoretical discussion of the structure, causes and consequences of affective experiences at work

150. Weiss LA, Westerhof GJ, Bohlmeijer ET (2016) Can we increase psychological well-being? The effects of interventions on psychological well-being: a meta-analysis of randomized controlled trials. PLOS ONE 11(6):e0158092. https://doi.org/10.1371/journal.pone.0158092

151. Wen J, Huang S (Sam), Hou P (2019) Emotional intelligence, emotional labor, perceived organizational support, and job satisfaction: a moderated mediation model. Int J Hosp Manag 81:120-130. https://doi. org/10.1016/j.ijhm.2019.01.009

152. Witt LA, Spector PE (2012) Personality and reactions to organizational politics. In: Politics in organizations. Routledge, pp 589-622

153. Zeidner M, Matthews G (2016) Ability emotional intelligence and mental health: social support as a mediator. Personal Individ Differ 99:196-199. https://doi.org/10.1016/j.paid.2016.05.008

154. Zhu Y, Li D (2015) Negative spillover impact of perceptions of organizational politics on work-family conflict in China. Soc Behav Personal Int J 43(5):705-714

\section{Publisher's Note}

Springer Nature remains neutral with regard to jurisdictional claims in published maps and institutional affiliations.

\section{Submit your manuscript to a SpringerOpen ${ }^{\circ}$ journal and benefit from:}

- Convenient online submission

- Rigorous peer review

- Open access: articles freely available online

- High visibility within the field

- Retaining the copyright to your article

Submit your next manuscript at $\boldsymbol{\nabla}$ springeropen.com 